\title{
Research on the Status and Mode of Agricultural Logistics Development in China
}

\author{
Xiaolan $\mathrm{Hu}^{1,2, a}$, Hui $\mathrm{Ye}^{1,2, b,{ }^{*}}$ and Mei Xie ${ }^{1,2, \mathrm{c}}$ \\ ${ }^{1}$ School of Business Administration, Wuhan Business University, Wuhan, 430056 China; \\ ${ }^{2}$ Development Research Center of Wuhan Modern Logistic, Wuhan, 430056 China. \\ ahelenhow001@163.com, , "b648980456 @qq.com, c253637228@qq.com
}

Keywords: Agricultural logistics, development mode.

\begin{abstract}
Agricultural production is inseparable from circulation. With the development of rural economy and the advancement of urbanization, the demand for agricultural logistics is getting higher and higher. Although in recent years there has been a significant increase in agricultural logistics, the integrity, directionality, efficiency, and efficiency of agricultural logistics are still at a low level, and various models and enterprises have more than sufficient vitality, but lack of integrity and synergy. This article first defines and recognizes the concept of agricultural logistics. On this basis, the current status of China's agricultural logistics development is analyzed. Then we summarize the existing five kinds of agricultural logistics modes in China, and analyze their characteristics, advantages and limitations, so as to obtain a more comprehensive understanding of China's agricultural logistics.
\end{abstract}

\section{Introduction}

Agricultural logistics is seen as a logistics activity centered on rural production and distribution. It mainly includes the logistics of agricultural production materials and the logistics of agricultural products. Based on the realistic characteristics of rural production and life, agricultural supplies, rural consumer goods, and bidirectional complementarity in the flow direction of agricultural product logistics we can define agricultural logistics (generalized) in such a way that it is the sum of the material flows involved in the overall process of the agricultural industrial chain and the logistics of rural consumer goods [1]. It includes: agricultural product logistics, agricultural production information logistics, rural consumer goods logistics, and agricultural recycling logistics.

\section{Status of Agricultural Logistics}

References are cited in the text just by square brackets [1]. (If square brackets are not available, slashes may be used instead, e.g. /2/.) Two or more references at a time may be put in one set of brackets $[3,4]$. The references are to be numbered in the order in which they are cited in the text and are to be listed at the end of the contribution under a heading References, see our example below.

From Reform and Opening, China's social consumer goods have been concentrated mainly at the municipal sales units. The retail sales of consumer goods in counties and sub-county units which play an important role in rural urbanization are not optimistic. The phenomenon of repeated store construction and the shortage of large-scale sales online stores in remote areas exist at the same time [2]. The construction of rural logistics facilities has a long payback period and the investment risks are relatively large, which further exacerbates the lack of circulation capacity of rural consumer goods.

The circulation of agricultural production materials in China has always been based on the state-owned companies and trading markets. In the past 30 years, under the government's policies, a large number it private agricultural production materials and circulation enterprises have grown rapidly, showing the diversification of sales channels and the decentralization of logistics. Although the way of circulation is still from the place of production to the transit place and the place of consumption via the main line and the branch line, and then through the township and village two 
levels of operating network distribution to its place of consumption, but its logistics flow channel is basically open [3]. However, these enterprises are small in scale, dispersive in their operations, poor in market competitiveness, and have not formed a certain concentration. In recent years, the emergence and development of various emerging of methods of it have injected new vitality into the development of agricultural production materials.

At the end of the 1970s, China basically established a logistics system for agricultural products, which played a significant role in promoting the development of rural economy in China. However, the quantity, scale, and level of it vary. The links of it mainly involve the decentralized management of fruits and vegetables, animal husbandry, aquaculture, forestry farmers and part of agricultural cooperatives, and a small number of state-owned farms. The processing link involves the agricultural product processing enterprises with relatively small scale of operation at and village level, and the large-scale agricultural product processing enterprises. In the aspect of storage and transportation, food systems, logistics parks and logistics companies, import and export companies, relevant transportation methods, transportation and warehousing departments and companies all play a role. In terms of sales, China has initially formed all levels of grain and oil, agricultural and sideline products, daily necessities and production materials, including the wholesale market as the center, urban and rural markets as the basis, supermarket chains, direct sales and distribution as the leading category, which basically realized the pattern of large-scale agricultural products and large circulation. Of course, there are still many problems in the logistics of agricultural products.

Rural residents in China generally lack the awareness of protecting the environment and saving resources. Garbage, livestock manure, crop straw are cluttered. Corresponding standards or technical guidelines for the recycling of agricultural waste are in an arbitrary state. Relevant administrative departments are lagging behind, and there are no corresponding incentives to encourage governance which make rural reverse logistics in a non-globalized and intensive plan.

\section{Mode of Agricultural Logistics}

\subsection{Traditional Mode.}

Traditional mode is also called wholesale market mode. This is under the circumstances that the quantity and transaction of agricultural products have soared, and the state has adopted corresponding policy measures to solve the contradiction between the production and circulation [. Established a large number of agricultural product wholesale markets, agricultural product specialty markets and agricultural product trade markets in various cities and regions. The main body of industrial chain of agricultural products at all levels is mainly connected through three levels of markets: the wholesale market of origin - the wholesale market of the land - the farmer's market (supermarket).

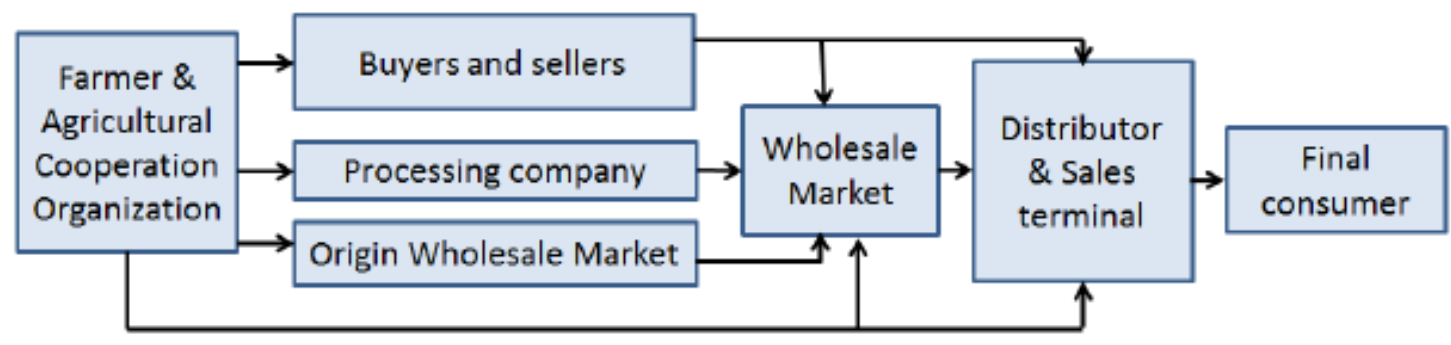

Fig 1. Traditional mode

Although this model enables the "small production" and "big market" to achieve a certain degree of docking, but there are limitations [4]. The first is the low efficiency. In the process of the continuous transfer of agricultural product ownership, because the business flow and logistics are not separated, the agricultural products must go through repeated trips, making the logistics of agricultural products long, cost, and loss increase. Moreover, because agricultural products are produced in a wide geographical area, too many intermediate links make the number of logistics entities involved much. It results in a low quality of logistics information and increasing the 
negotiation costs in transactions. Because of its extensive circulation, the transaction is more random and lacks stability, making it difficult to respond to market demands more efficiently.

At the same time, the logistics of life and production materials in rural areas is separated from the logistics of agricultural products [5]. They depend on the production and marketing of agricultural enterprise, the marketing market, and the rural sales department and retail outlets which showing the diversification of sales channels and the decentralization of logistics.

\subsection{Supply Chain Mode.}

The agricultural supply chain model correlates and integrates all links and entities involved in the production, circulation, and consumption of agricultural products. Other related non-agricultural products and the existing agricultural product supply chain are basically separated, which depend their traditional channels to responsible for their circulation and logistics [6]. As far as the current reality is concerned, the agricultural product supply chain mainly includes the "company + farmer" model, the "company + base + farmer" model, the "company + agricultural association + farmer" model, the "company + cooperative + farmer", and the "farmer household company". The specific forms are various, but the general principle is the integration of production and sales of the supply chain, which has streamlined the circulation and logistics channels, reduced transaction costs, and optimized product quality. However, the focus of this model is on the circulation of agricultural products. It involves a relatively shallow degree in other aspects of agricultural logistics and is in an auxiliary position. The issue of "going out" of agricultural products has been well achieved, but it has not been possible to fundamentally solve the overall problems of agricultural logistics. At the same time, the leading supply chain is generally a processing company. Their advantage is not the circulation of agricultural products, and it also leads to high costs and low efficiency.

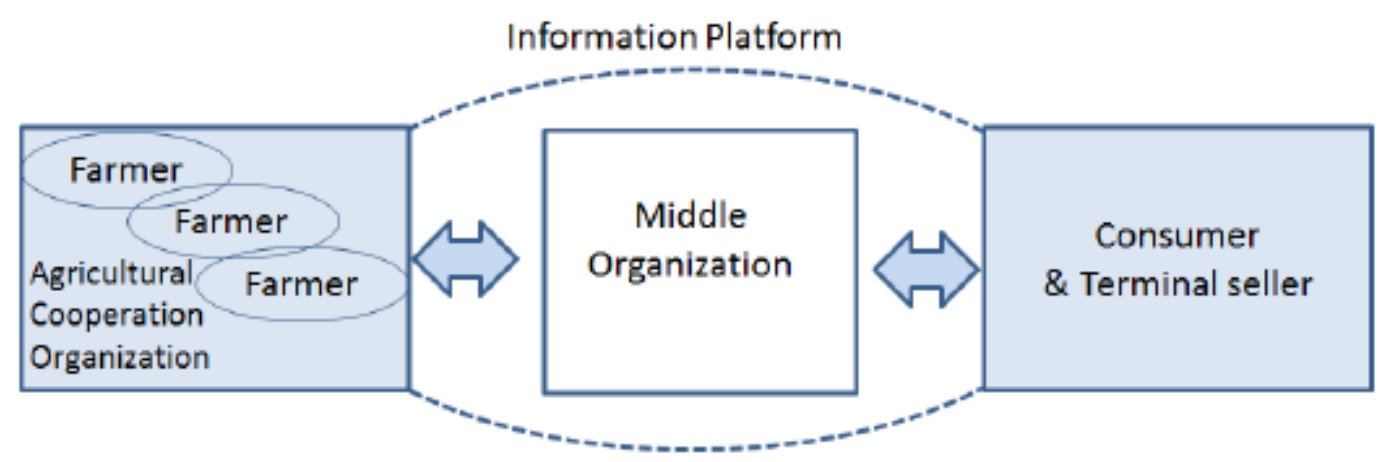

\subsection{TPL Mode.}

Fig 2. Supply chain mode

China's TPL mode is based on agricultural product logistics, with the aid of agricultural product logistics companies or logistics alliances to provide agricultural product logistics services. Although it also includes a part of agricultural production materials and logistics of rural consumer goods, it only stays in scattered and sporadic functional services, lack of collaboration and integrity [7]. At the end of the last century, China increased the investment in agricultural product logistics, optimized the allocation of transportation companies and warehousing companies under the traditional system, transformed it into a TPL company. This model can achieve the integration of resources and functions, improve the specificity and efficiency of logistics infrastructure and assets, integrate agricultural logistics processes, and improve the level of information.

TPL companies started relatively late, mainly providing basic functions such as storage and transportation, and higher-level value-added services are still in a perfect stage. At the same time, the TPL Company has a limited scale, and there are still great limitations in the advantages of integration and scale. Although this model has achieved scale integration and efficiency improvement on agricultural products, it still stays on simple return delivery to solve agricultural production materials and rural consumer goods logistics. 


\subsection{E-commerce Mode.}

Apply the currently booming e-commerce to the circulation of agricultural products, and provide services such as online transactions, electronic payments, and logistics distribution through the e-commerce platform for the circulation of agricultural products. Farmers, agricultural cooperatives, wholesalers, retailers, end-customers, etc. are connected through the Internet, and some agricultural production materials and rural consumer goods distribution companies also have networking. In order to complete the coordination, control, and management of the production and sales process of agricultural products, the intermediate process service between the network front-end and the final client is realized, and information is highly shared. It also optimized the flow of agricultural product logistics based on user needs and improved the operational efficiency of agricultural product logistics.

At this stage, this model is mainly applied to agricultural products and has not yet been integrated with agricultural production materials, rural living materials, and agricultural recycling logistics [8]. Only when the TPL and e-commerce are more developed and supplemented with an efficient public information platform, can it achieve its desired results. To achieve full coverage of agricultural logistics, it also needs a large number of cooperation organizations, processes and management tools, and the actual application is difficult.

\subsection{Agricultural Logistics Park Mode.}

Agricultural logistics parks can cover most of the agricultural socialized service systems we have mentioned, referring to the suppliers of agricultural socialized services - cooperative organizations, leading enterprises, and other non-governmental entities. They have even introduced government and agricultural scientific research units [9]. By integrating the functions of agricultural logistics, supplemented by an advanced information technology platform, it provides modern and comprehensive logistics services for agricultural logistics entities. At the same time, it highlights the role of logistics in linking and interaction between urban and rural areas, and absorbs the production of agricultural production materials or circulation enterprises and rural living materials circulation enterprises [10]. It integrates agricultural resources, rural consumer goods circulation and logistics, and agricultural product logistics to achieve bidirectional circulation. The logistics park becomes a full-service platform integrating production, processing, retailing, logistics, and the entire agricultural logistics and production and sales leader.

However, according to the current development situation, the development of China's agricultural logistics park is still in its infancy, and it will take some time for its functions and huge organizational platform effects to be realized. However, many agricultural product wholesale markets or agricultural product logistics parks have become a substantial agricultural logistics park because of their pioneering and high degree of market recognition, and their continuous extension of service scope along with the growth of agricultural demand.

If you follow the "checklist" your paper will conform to the requirements of the publisher and facilitate a problem-free publication process.

\section{Summary}

At present, these five modes exist in the reality of China's agricultural logistics and play an important role in different regions and fields. By synthesizing the characteristics of the above modes, we can recognize that they all have their own limitations. These modes have outstanding advantages in some areas and have solved the problem of "going out" of agricultural products, but lack integrated solutions for agricultural logistics. Second, they are still confined to a certain area. Although core companies play a role in organizing and coordinating control, they lack stable and continuous organizational guarantees and platform foundations. Due to the existence of regional interests and market barriers, they have to additionally established services for these non-core businesses which intensified the separation of the agricultural industry chain, weaken the division of labor between regions and industries. 


\section{Acknowledgments}

Hui Ye is the corresponding author. This paper is supported by project of The National Social Science Fund of China (18BJY138).

\section{References}

[1]. Yossi Steffi. Logistics Clusters Delivering Value and Driving Growth. China Machine Press, 2015, p. 152-161.

[2]. Zhang Ya. Countermeasures and suggestions for the development of agricultural logistics in China. China Business and Market.(2006)No.3,p.79-81

[3]. Jiang Fan, Li Yehuda. The Construction of Modern Agricultural Logistics Development Model and Evaluation Index System in China. Logistics technology.(2014) No.1,p.152-155

[4]. Report on the development of rural logistics in China. China Rural Logistics Development Report Rural Modern Logistics Research Center Task Force.2013,p31-50

[5]. Ren Baoping, Ren Zongzhe. Research on the Coordinated Urban-rural Perspective of Two-way Circulation. China Economic Publishing House,2011,p.101-112

[6]. Hubei Pengdun Hanguang Agricultural Logistics Park Operation Plan. Wuhan University Logistics and Supply Chain Research Centre, 2014, p. 25-32.

[7]. Huang, S. and F. Gale, China's Rising Fruit and Vegetable Exports Challenge U.S Industries. Electronic Outlook Report from the Economic Research Service. Department of Agriculture, Washington, DC, 2012, p. 82-96.

[8]. Wajszczuk. Karol, Wawrzynowicz. Jack, Slaw zincky. Boguslaw. A Model of an Integration System for Operations and Cost Data Designed to Control Logistics Processes in Agricultural Enterprises.Contemporary Economics, Vol. 24(2011) No.3,p .48-58

[9]. Shore, B. Information Sharing in Global Supply Chain Systems.Journal of Global Information Technology Management, Vol. 6(2011) No.2,p .27-50

[10]. Naves M. F. Zylbersztajn D. E. M. Neves. The orange juice food chain. Proceedings of the 3rd International Conference on Chain Management in Agribusiness and the Food Industry. Wageningen Agricultural University Press, 1998,p.437-446

[11]. Information on: www.zgny.com.cn

[12]. Information on: www.chinawuliu.com.cn

[13]. Information on: www.xiangcun.com.cn 